\title{
Determining the specific microbial populations and their spatial distribution within the stromatolite ecosystem of Shark Bay
}

\author{
Falicia Goh ${ }^{1}$, Michelle A Allen ${ }^{1}$, Stefan Leuko ${ }^{2}$, Tomohiro Kawaguchi ${ }^{3}$, Alan W Decho ${ }^{3}$, \\ Brendan P Burns ${ }^{1,2}$ and Brett A Neilan ${ }^{1,2}$ \\ ${ }^{1}$ School of Biotechnology and Biomolecular Sciences, University of New South Wales, Sydney, New South \\ Wales, Australia; ${ }^{2}$ Australian Centre for Astrobiology, University of New South Wales, Sydney, New South \\ Wales, Australia and ${ }^{3}$ Department of Environmental Health Sciences, Arnold School of Public Health, \\ University of South Carolina, Columbia, SC, USA
}

\begin{abstract}
The stromatolites at Shark Bay, Western Australia, are analogues of some of the oldest evidence of life on Earth. The aim of this study was to identify and spatially characterize the specific microbial communities associated with Shark Bay intertidal columnar stromatolites. Conventional culturing methods and construction of 16S rDNA clone libraries from community genomic DNA with both universal and specific PCR primers were employed. The estimated coverage, richness and diversity of stromatolite microbial populations were compared with earlier studies on these ecosystems. The estimated coverage for all clone libraries indicated that population coverage was comprehensive. Phylogenetic analyses of stromatolite and surrounding seawater sequences were performed in ARB with the Greengenes database of full-length non-chimaeric 16S rRNA genes. The communities identified exhibited extensive diversity. The most abundant sequences from the stromatolites were $\alpha$ - and $\gamma$-proteobacteria $(58 \%)$, whereas the cyanobacterial community was characterized by sequences related to the genera Euhalothece, Gloeocapsa, Gloeothece, Chroococcidiopsis, Dermocarpella, Acaryochloris, Geitlerinema and Schizothrix. All clones from the archaeal-specific clone libraries were related to the halophilic archaea; however, no archaeal sequence was identified from the surrounding seawater. Fluorescence in situ hybridization also revealed stromatolite surfaces to be dominated by unicellular cyanobacteria, in contrast to the sub-surface archaea and sulphate-reducing bacteria. This study is the first to compare the microbial composition of morphologically similar stromatolites over time and examine the spatial distribution of specific microorganismic groups in these intertidal structures and the surrounding seawater at Shark Bay. The results provide a platform for identifying the key microbial physiology groups and their potential roles in modern stromatolite morphogenesis and ecology.

The ISME Journal (2009) 3, 383-396; doi:10.1038/ismej.2008.114; published online 18 December 2008

Subject Category: microbial population and community ecology
\end{abstract}

Keywords: stromatolite; cyanobacteria; FISH; microbial community; geomorphology; phylotype; halophilic archaea

\section{Introduction}

Stromatolites are abundant throughout the Earth's geological records. The oldest examples of these preserved formations are more than 3 billion years old and are found mainly in Western Australia and South Africa (Lowe, 1980; Walter et al., 1980; Byerly et al., 1986). Recent studies have reflected a wide-

Correspondence: BA Neilan, School of Biotechnology and Biomolecular Sciences, University of New South Wales, Sydney, New South Wales 2052, Australia.

E-mail: b.neilan@unsw.edu.au

Received 14 July 2008; revised 10 October 2008; accepted 20 October 2008; published online 18 December 2008 spread and growing acceptance of the oldest stromatolites from the Pilbara region of Western Australia as biogenic (Allwood et al., 2006). However, the limited information preserved in fossil stromatolites has prompted studies on extant systems as crucial to understanding the process of their formation. Prominent examples of modern stromatolites can be found in the hypersaline region of Hamelin Pool, Western Australia (Hoffman, 1976; Playford and Cockbain, 1976), and in the open marine waters of Exuma Sound, Bahamas (Dravis, 1983; Reid et al., 2000). These modern analogues provide us with a template of how Earth and its early biosphere may have co-evolved. 
Sediment trapping and binding and/or mineral precipitation by microorganisms led to the formation of the Bahaman stromatolites (Reid et al., 2000). In particular, filamentous cyanobacteria of the genus Schizothrix were shown to be responsible for the binding and trapping of sand grains, whereas coccoid cyanobacterial populations provided structural support for the growth of the stromatolites. In addition, both heterotrophic aerobic and anaerobic bacteria, which synthesize low-molecular weight organic compounds and amorphous exopolymers, were also present in these structures (Visscher et al., 1998). In contrast to the Bahaman stromatolites, the Shark Bay communities exhibit a greater diversity of archaea, cyanobacteria and heterotrophic bacteria (Burns et al., 2004; Papineau et al., 2005; Leuko et al., 2007). Shark Bay stromatolite communities are characterized by cyanobacteria belonging to the genera Synechococcus, Xenococcus, Microcoleus, Leptolyngbya, Plectonema, Symploca, Cyanothece, Pleurocapsa, Nostoc and Prochloron (Burns et al., 2004; Papineau et al., 2005). These initial studies identified more than 20 of the 52 known divisions of bacteria, as well as archaeal communities, including both Euryarchaeota and Crenarchaeota gene sequences. Comparison between stromatolites of differing morphology was also related to specific changes in the microbial community present. Recent studies on both Shark Bay and Bahaman stromatolites have revealed that eukaryotes are scarce in these formations (Reid et al., 2000; Burns et al., 2004; Papineau et al., 2005), though a variety of flagellates have been documented from Shark Bay (Al-Qassab et al., 2002). It has been proposed that stromatolites thrive in environments that exclude many higher organisms, particularly those that may graze on the resident microorganisms.

To date there have been no studies comparing the microbiology of morphologically similar stromatolites over temporal scales, or assessing the prokaryotic populations of the surrounding seawater. This latter feature is particularly important in attempting to assign populations specific to the geological morphogenesis and to further our understanding of the ecology and dynamics of modern stromatolite communities. Here, apart from these microbial diversity and functional assignments, scanning electron microscopy and fluorescence in situ hybridization were also performed on stromatolite sections to examine the spatial distribution and interaction of specific microorganism groups within these stromatolites.

\section{Materials and methods}

\section{Sample description and sample sites}

Hamelin Pool in Western Australia spans an area of ca. $1220 \mathrm{~km}^{2}$ with an average tidal range of ca. $60 \mathrm{~cm}$ (Logan and Cebulski, 1970). High net evaporation rates and average water temperatures throughout the year between 17 and $27^{\circ} \mathrm{C}$ create a hypersaline environment with at least twice the salinity of seawater (Arp et al., 2001). Intertidal columnar stromatolites (Figure 1) were collected during the

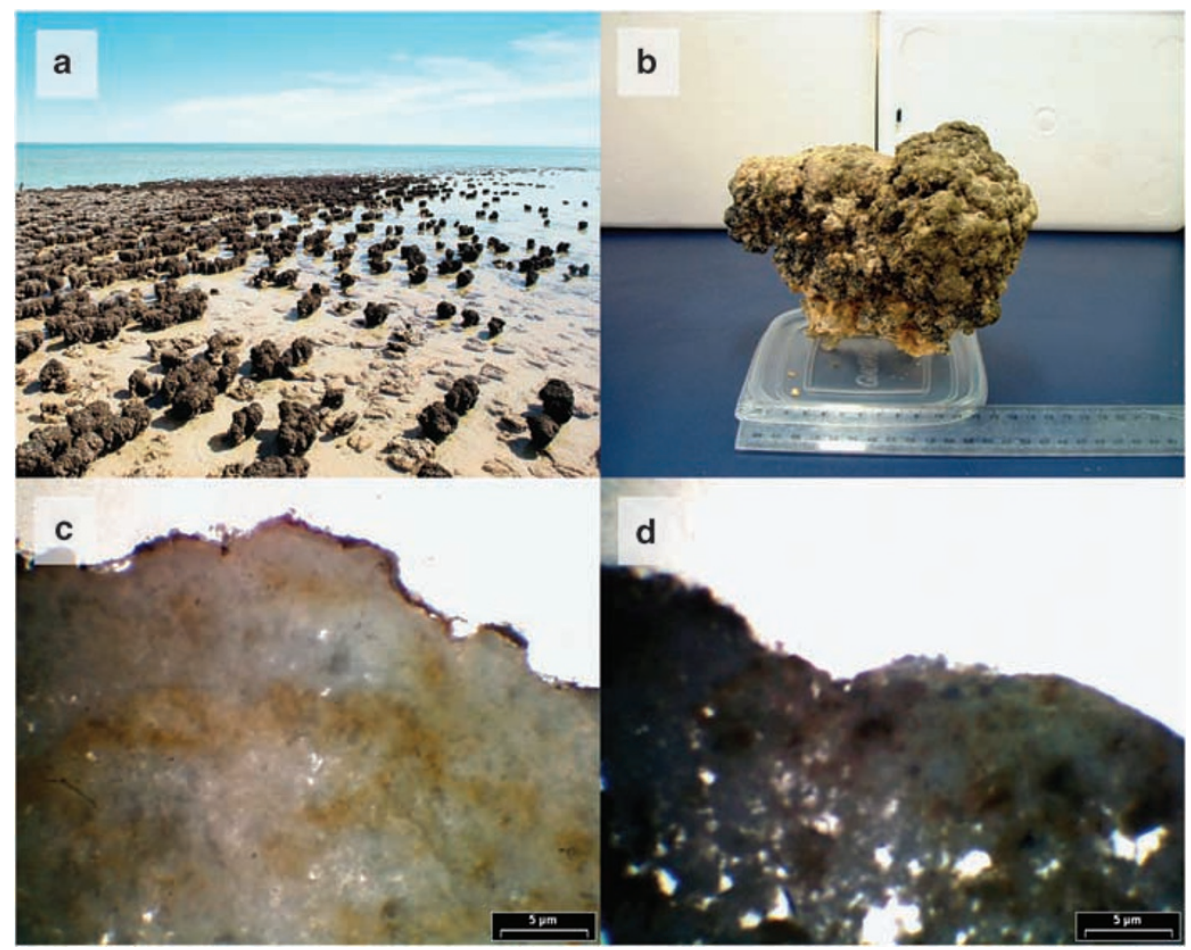

Figure 1 Images of stromatolites and the sample site at Hamelin Pool, Shark Bay. (a) Low tide at Telegraph Point showing stromatolites. (b) Sample HPS2. (c) A slide of sample HPS1 (Burns et al. (2004)) and (d) a slide of sample HPS2. Both (c) and (d) were embedded in epoxy resin and sectioned to a width of $30 \mu \mathrm{m}$; photograph taken using light microscopy (magnification $=\times 4$ ). 
late afternoon in November 2002 from Telegraph Point $\left(26^{\circ} 25^{\prime} 00^{\prime \prime} \mathrm{S}, 11 \mathrm{H}^{\circ} 13^{\prime} 05^{\prime \prime}\right)$ on the south eastern shore of Hamelin Pool, Shark Bay, Western Australia, using methods described earlier (Burns et al., 2004). Samples were collected during low tide and a rock hammer was used to physically remove small sections with a vertical interval of $\sim 2 \mathrm{~cm}$ from the top of the stromatolite. Seawater surrounding the stromatolites was collected in sterile containers immediately before the collection of stromatolite samples.

Samples were placed in sterile specimen bags and stored in the dark at $4{ }^{\circ} \mathrm{C}$ during transportation. All samples were collected and handled with sterile instruments throughout the course of the study. The stromatolite sample analysed here was designated as HPS2 and another stromatolite surface section collected from the same location was designated as HPS1 (Burns et al. 2004). Although both samples were obtained from different stromatolites, they were obtained from morphologically identical columnar stromatolites in the intertidal region, both exhibiting a dark green and black pustular surface. These samples (HPS1 and HSP2) also have the same morphology as the stromatolite sample (HPIRR) analysed by Papineau et al. (2005). In contrast, sample HPDOM (Papineau et al., 2005) had a smooth domal surface. All samples were collected in the late afternoon. The interior of the sample analysed in this study consisted of fine grains as shown in the image of the cross-section from HPS2 (Figure 1d). The interior of HPS1 (Figure 1c) also showed that this sample consisted of similar fine grains. These both resembled the intertidal finegrained stromatolites built by cyanobacteria as described in earlier studies by Awramik and Riding (1988). All samples were stored at $4{ }^{\circ} \mathrm{C}$ and DNA extraction and microorganism isolation were conducted immediately upon sample return.

\section{Scanning electron microscopy}

Fractured stromatolite samples were fixed in 3\% glutaraldehyde solution, washed with $0.1 \mathrm{M}$ sodium cacodylate buffer and stored at $4{ }^{\circ} \mathrm{C}$. The samples were dehydrated in an ethanol series (50-100\%), vacuum dried and sputter coated with gold using EmiTech K550 $\times$ gold sputter coater. Specimens were examined in a Leica Cambridge S360 scanning electron microscope set at an accelerating voltage of $20.0 \mathrm{kV}$ with a lens-to-specimen working distance of $25 \mathrm{~mm}$ and a beam current of $100 \mathrm{pA}$.

\section{Culturing and isolation}

Isolation of bacteria, cyanobacteria and archaea from HPS2 and seawater was carried out by modifying BG-11 media (Rippka et al., 1981), Luria-Bertani media (Sambrook et al., 1989) and DSM97 (DasSarma et al., 1995), respectively. The salt concentrations of the different media were modified by the addition of $\mathrm{NaCl}$ (852 mM), $\mathrm{KCl}$ (18.6 mM), $\mathrm{CaCl}_{2}$ (18.4 mM), $\mathrm{MgCl}_{2}(90 \mathrm{mM})$ and $\mathrm{MgSO}_{4}(54 \mathrm{mM})$. This was conducted to mimic the hypersaline conditions of Hamelin Pool as described earlier (Burns et al., 2004), to isolate heterotrophic bacteria, cyanobacteria and halophilic archaea from this hypersaline environment. Owing to the higher concentration of sodium chloride in DSM97, no addition of this salt was made to this medium. To further facilitate the isolation of the slow-growing halophilic archaea from the faster growing bacteria, three antibiotics at $100 \mathrm{mg} \mathrm{ml}^{-1}$ (streptomycin, penicillin and ampicillin) were added to the modified DSM97 media (Wais, 1988).

\section{DNA isolation and PCR amplification of 16S rRNA genes}

Genomic DNA extraction of isolates was performed with an extraction protocol utilizing xanthogenate (Tillett and Neilan, 2000). The total genomic DNA from ground stromatolite was extracted using the TNE buffer extraction protocol (Neilan et al., 2002). Modifications to this protocol were carried out to improve cell lysis by extending the lysozyme step $(>1 \mathrm{~h})$ and the inclusion of four freeze-thaw cycles. Genomic material from two litres of seawater was concentrated by centrifugation and then extracted using the same extraction protocol as for the stromatolites. PCRs were performed using $1 \mathrm{U}$ Taq polymerase (Fischer Biotech, Perth, Western Australia, Australia), $2.5 \mathrm{mM} \mathrm{MgCl}_{2}, 10 \times$ Taq polymerase buffer (Fischer Biotech), $0.2 \mathrm{mM}$ dNTPs (Fischer Biotech) and $0.2 \mathrm{pM}$ of each primer. Thermal cycling was performed in a GeneAmp PCR System 2400 Thermocyler (Perkin Elmer, Norwalk, CT, USA). Primer pairs used for the amplification of the bacterial, cyanobacterial and archaeal 16S rRNA genes were 27F1(5'-AGAGTTTGATCCTGGCTCA G-3')/1494Rc (5'-TACGGTTACCTTGTTACGAC-3')/ 809R (5'-GCTTCGGCACGGCTCGGGGTCGATA-3') and $21 \mathrm{~F}\left(5^{\prime}\right.$-TTCCGGTTGATCCYGCCGGA-3')/958R (5'-YCCGGCGTTGAMTCCAATT-3'), respectively. Thermal cycling conditions for the amplification of bacterial 16S rRNA genes were initial denaturation step at $92{ }^{\circ} \mathrm{C}$ for $2 \mathrm{~min}$, followed by 30 cycles of denaturation at $92{ }^{\circ} \mathrm{C}$ for $10 \mathrm{~s}$, primer annealing at $52^{\circ} \mathrm{C}$ for $15 \mathrm{~s}$, strand extension at $72^{\circ} \mathrm{C}$ for $90 \mathrm{~s}$ and a final extension step at $72{ }^{\circ} \mathrm{C}$ for $7 \mathrm{~min}$. Thermal cycling conditions for the amplification of cyanobacteria were as per standard protocols (Jungblut et al., 2005), and the amplification of archaeal $16 \mathrm{~S}$ rRNA genes was carried out as described earlier (DeLong, 1992).

\section{Construction of $16 S$ rDNA clone libraries}

Amplified archaeal-, universal bacterial- and cyanobacterial-specific 16S rRNA gene PCR products from total genomic DNA extracted from HPS2 and seawater were cloned into the p-Gem T Easy Vector 
System (Promega, Madison, WI, USA). Ligations and transformations were performed according to the manufacturer. For each sample and set of primers used, at least 100 positive (insert containing) clones were selected. Restriction fragment length polymorphism (RFLP) analysis was performed with PCR products using restriction enzymes AluI and ScrF1 (Fermentas, Hanover, MD, USA) (Jungblut et al., 2005). Clones were then grouped according to their different restriction patterns and a clone representing each pattern was sequenced. Automated sequencing was carried out using the PRISM Big Dye cycle sequencing system and ABI 3730 Capillary Applied Biosystem (Foster City, CA, USA) using Polymer 7.

\section{Estimation of microbial diversity}

Distance matrices were generated in ARB using the neighbour-joining method with the Jukes and Cantor correction. The program DOTUR (Schloss and Handelsman, 2005) was used to cluster sequences into operational taxonomic units by pair-wise identity (95-100\% ID) with a furthest-neighbour algorithm and a precision of 0.01. Rarefaction curves, richness estimations (Chao1) and diversity indices (Shannon-Wiener) were calculated using DOTUR with default settings and 1000 random sample repetitions. Coverage $(C)$ values were calculated by the method of Good with the equation $C=[1-(n / N)] \times 100$, where $n$ is the number of phylotypes in a sample represented by one clone (singletons) and $N$ is the total number of clones examined (Good, 1953).

\section{Phylogenetic sequence analysis}

All sequences were analysed for chimaeras using methods described by Huber et al. (2004) and Cole et al. (2003). Chimaeras were not detected in the clones obtained. Sequence identities were determined by Basic Local Alignment Search Tools (BLAST) results and phylogenetic analysis. The $16 \mathrm{~S}$ rRNA gene sequences were aligned and analysed using the ARB software package (Ludwig et al., 2004). The resulting alignments were manually checked and corrected when necessary. Phylogenetic trees were constructed using the maximum likelihood method (default parameters for ARB and fastDNAml) and the alignment of near full-length sequences ( $>1000 \mathrm{bp}$ ) of reference strains. Aligned partial $16 \mathrm{~S}$ rRNA gene sequences $(<1000 \mathrm{bp})$ were then inserted without changing the overall tree topology using the parsimony tool within ARB. This was necessary as sequences from a study on these stromatolite populations conducted by Papineau et al. (2005), samples designated as HPDOM and HPIRR, targeted different regions of the $16 \mathrm{~S}$ rRNA genes as compared with this study and the study by Burns et al. (2004). Bootstrap values were obtained for branching patterns by using the
PHYLIP software package (Retief, 2000), and values $>50 \%$ were included for the main nodes of the tree. 16S rRNA gene sequences from earlier studies on the Shark Bay stromatolites (Burns et al., 2004; Papineau et al., 2005) were included for the determination of differences in the populations.

\section{Fluorescence in situ hybridization of archaea and sulphate-reducing bacteria}

Stromatolite samples $(1 \mathrm{~cm}$ vertical section from the surface) for fluorescent in situ hybridization were fixed in $4 \%$ paraformaldehyde solution, washed with 1:1 phosphate-buffered saline-ethanol buffer and stored at $4{ }^{\circ} \mathrm{C}$ until required. Samples were then embedded in epoxy resin and sectioned to a width of $30 \mu \mathrm{m}$. Hybridization buffer containing an appropriate concentration of formamide and $50 \mathrm{ng}$ of each probe (SRB385 5'-CGGCGTCGCTGCGTCAGG-3' or Arch915 5'-GTGCTCCCCCGCCAATTCCT-3') was applied to the slides, followed by incubation at $46{ }^{\circ} \mathrm{C}$ for $2 \mathrm{~h}$. The samples were washed for 10-15 min in wash buffer pre-heated to $48^{\circ} \mathrm{C}$ and subsequently rinsed with Milli-Q water. The slides were dried in the dark. Mountant and coverslip were applied, viewed and imaged using a confocal laser scanning microscope with argon-krypton laser.

\section{Accession numbers}

Sequences of the 16S rDNA clones and isolates are available under GenBank accession numbers EF150676-EF150838.

\section{Results and discussion}

Microbial communities present in the stromatolites and the seawater surrounding these formations in Shark Bay were analysed with molecular phylogenetic methods. Isolation of cultivable microorganisms was also achieved by modifying the three culture media (Luria-Bertani, BG11 and DSM97 media) used in this study. The stromatolite sample (HPS2) analysed here had an irregular morphology and a dark green and black pustular surface. This is the same morphology as that described for both the samples studied previously, HPIRR (Papineau et al., 2005) and HPS1 (Burns et al., 2004). The sample interior of HSP2 consisted of fine grains as shown in the image of a cross-section (Figure 1d), similar to the cross-section of HPS1. Scanning electron micrographs indicated an association between carbonate and sand grains with filamentous bacteria (Figure 2), and boreholes, approximately $5-10 \mu \mathrm{m}$ in diameter, were also evident. It is difficult at this stage to assign exact identities to these borers in the Shark Bay stromatolites; however, potential candidates include the range of unicellular coccoid cyanobacteria identified here (Table 1). These findings are consistent with the study carried out on Bahaman stromatolites (Reid et al., 2000), where boring 


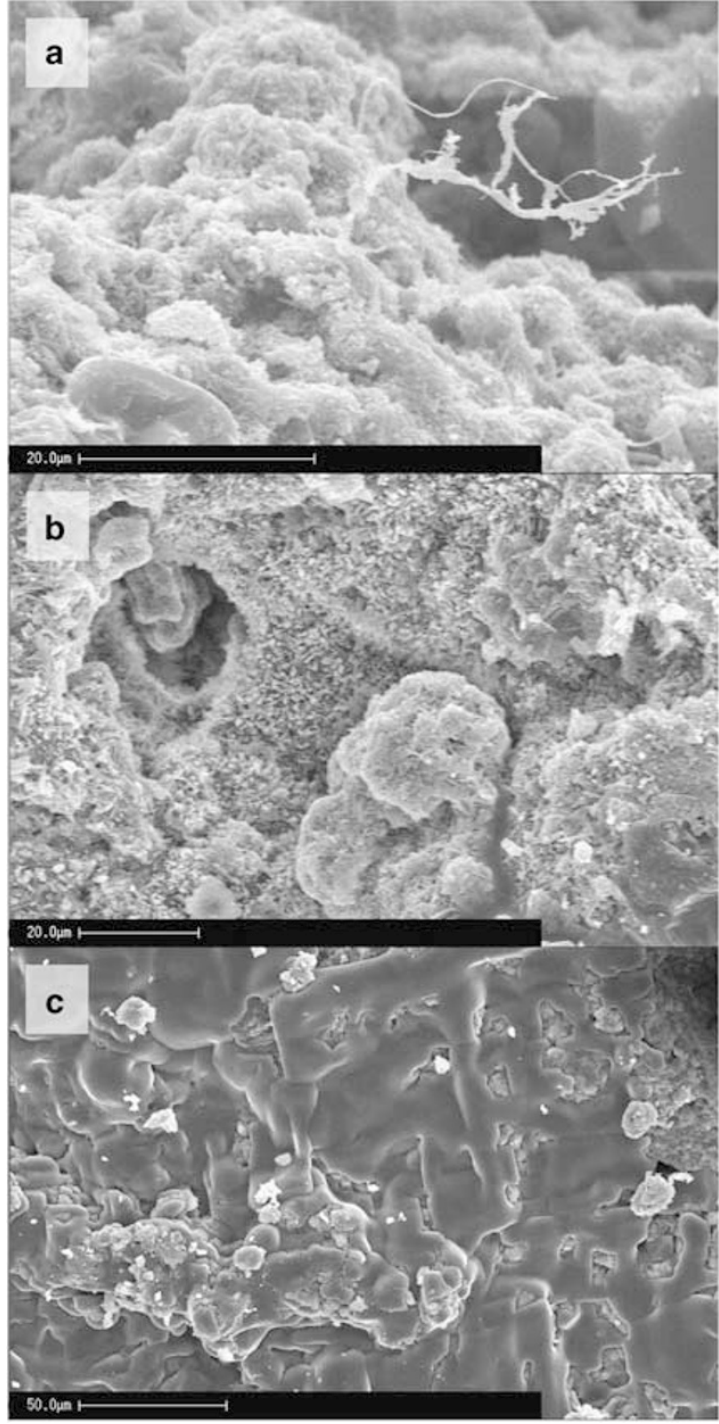

Figure 2 Scanning electron micrographs of Hamelin Pool stromatolite (HPS2). (a) Filamentous cyanobacteria binding carbonate sand grains. (b) Borehole, as shown by the arrow, is approximately $5-10 \mu \mathrm{m}$ in diameter filled with needle-like microcrystalline structure, most probably aragonite (another form of calcium carbonate), and (c) welding of carbonate sand grains and in-filling of boreholes as a result of continued microboring.

activities of microorganisms (microboring) was characterized by boreholes surrounded by needlelike aragonite crystals. Lithified layers of micritized carbonate sand grains were also evident (Figure 2), and this is likely to be a result of continuous microboring.

Isolation of microorganisms from stromatolite sample HPS2 and surrounding seawater

A total of 25 archaeal isolates and 63 bacterial isolates (of which 42 isolates belonged to cyanobacterial genera) were cultivated. Their identities were determined based on GenBank BLAST analysis of their 16S rRNA genes. All 25 archaeal isolates showed a maximum of only $92 \%$ identity to
Halobacterium NCIMB 718, an uncharacterized halophilic archaeon. One of these isolates was determined to be a new species belonging to the genus Halococcus (Goh et al., 2006). Bacteria belonging to the genera Bacillus, Salinivibrio, Halomonas, Marinobacter, Porphyrobacter, Idiomarina and two isolates with highest identity to the bacteria K2-13 and K3 were cultured from HPS2 (summarized in Table 1). Isolates with similarity to Alteromonas, Vibrio, Paracoccus and Roseibium were cultivated from the seawater. The cyanobacterial isolates had closest identity to Euhalothece, Gloeocapsa, Cyanothece, Oscillatoria, Geitlerinema, Xenococcus, Chroococcidiopsis, Gloeothece, Lyngbya and Dermocarpella (Table 1). No cyanobacteria were isolated from the surrounding seawater.

\section{Clone library analysis of HPS2 and surrounding seawater}

Amplification of $16 \mathrm{~S}$ rDNA using universal bacterial, specific cyanobacterial and archaeal primers, and subsequent clone library construction was conducted on both total community DNA from the finely ground stromatolite samples and the surrounding seawater. Unique clones were identified by RFLP analysis. Clones of representative RFLP types were sequenced bi-directionally and compared with known sequences by BLAST analysis. From the archaeal clone libraries (93 clones), 10 RFLP groups were identified with BLAST results of sequences having closest identity to halophilic archaea. No archaeal 16S rRNA genes were amplified from the genomic DNA isolated from the seawater. Thirty-three unique RFLP groups were obtained from the stromatolite bacterial clone libraries (85 clones), whereas 19 groups were obtained from the seawater libraries (94 clones). In HPS2, the highest proportion of sequences were related to $\alpha$-proteobacteria $(29 \%)$ and $\gamma$-proteobacteria $(29 \%)$, whereas the majority of clones in the seawater had sequence identities related to $\alpha$ proteobacteria (69\%) (Figure 3). A total of 96 clones were obtained for the stromatolite cyanobacterial library, with another 82 clones obtained from the seawater. Five groups were identified from the RFLP analysis of the stromatolite cyanobacterial library whereas eight groups were obtained from the seawater. The relative abundance of cyanobacterial clones is shown in Figure 3. The most abundant clones from HPS2 were affiliated with Gloeothece $(52 \%)$ and Gloeocapsa (42\%). The most abundant clones $(56 \%)$ from the seawater cyanobacterial library were related to Euhalothece.

\section{Estimated coverage and richness}

The coverage and richness of the clone libraries were assessed by the method of Good (1953) for the calculation of coverage, the non-parametric estimator Chao1 for richness (Chao, 1984) and the 
Table 1 Summary of bacteria isolated from HPS2 and seawater surrounding Shark Bay stromatolites

\begin{tabular}{|c|c|c|c|c|c|c|}
\hline \multirow[t]{2}{*}{ Sample } & \multirow[t]{2}{*}{ Media } & \multirow[t]{2}{*}{ Isolate ID } & \multirow[t]{2}{*}{ Accession no. } & \multicolumn{3}{|c|}{ Sequence analysis } \\
\hline & & & & Nearest relative in GenBank ${ }^{\mathrm{a}}$ & $\%$ Identity & Accession no. \\
\hline \multirow[t]{20}{*}{ HPS2 } & \multirow[t]{20}{*}{$\mathrm{LB}^{\mathrm{b}}$} & HSB25 & EF150759 & Bacillus sp. SD-18 & 98 & AF326372 \\
\hline & & HSB26 & EF150761 & Bacillus sp. BA-54 & 95 & AY557616 \\
\hline & & HSB28 & EF150762 & Bacillus hwajinpoensis & 99 & AF541966 \\
\hline & & HSB29 & EF150758 & Bacillus marismortui strain 123 & 99 & AJ009793 \\
\hline & & HSB9 & EF150760 & Halomonadaceae bacterium LA44 & 99 & AF513453 \\
\hline & & HSB55 & EF150747 & Bacterium K2-13 & 99 & AY345436 \\
\hline & & HSB30 & EF150749 & Bacillus sp. PL30 & 98 & AF326370 \\
\hline & & HSB31 & EF150750 & Halobacillus sp. D-8 & 95 & AY351395 \\
\hline & & HSB32 & EF150752 & Halobacillus trueperi strain GSP38 & 99 & AY505522 \\
\hline & & HSB13 & EF150753 & Marinobacter sp. MED104 & 98 & AY136120 \\
\hline & & HSB14 & EF150754 & Salinivibrio costicola strain GSP14 & 97 & AY553070 \\
\hline & & HSB33 & EF150755 & Bacillus sp. SG-1 & 98 & AF326373 \\
\hline & & HSB34 & EF150757 & Bacillus litoralis & 99 & AY608605 \\
\hline & & HSB8 & EF150748 & Halomonas alimentaria strain GSP27 & 98 & AY553077 \\
\hline & & HSB10 & EF150751 & Idiomarina sp. NT N118 & 99 & AB167034 \\
\hline & & HSB35 & EF150742 & Bacillus megaterium strain SAFB-011 & 99 & AY167865 \\
\hline & & HSB36 & EF150744 & Bacillus sp. KMM 3737 & 97 & AY228462 \\
\hline & & HSB6 & EF150743 & Porphyrobacter tepidarius DSM10594 & 97 & AF465839 \\
\hline & & HSB37 & EF150745 & Bacillus firmus & 97 & AJ509007 \\
\hline & & HSB56 & EF150746 & Bacterium K34 & 97 & AY345475 \\
\hline \multirow[t]{7}{*}{ Seawater } & & SWB5 & EF150705 & Alteromonas sp. V4.BE.32 & 98 & AJ244758 \\
\hline & & SWB6 & EF150706 & Vibrionaceae bacterium PH25 & 97 & AF513466 \\
\hline & & SWB3 & EF150700 & Paracoccus sp. MBIC 4036 & 92 & AB025192 \\
\hline & & SWB4 & EF150701 & Roseibium denhamense & 98 & D85832 \\
\hline & & SWB7 & EF150702 & Alteromonas sp. NBF18 & 97 & AF343939 \\
\hline & & SWB8 & EF150703 & Pseudoalteromonas sp. A25 & 98 & AF227237 \\
\hline & & SWB9 & $\mathrm{EF} 150704$ & Vibrionaceae bacterium PH25 & 99 & AF513466 \\
\hline \multirow[t]{12}{*}{ HPS2 } & \multirow[t]{12}{*}{ BG-11 ${ }^{\mathrm{a}}$} & HSC29 & EF150800 & Euhalothece sp. strain MPI95AH13 & 96 & AJ000710 \\
\hline & & HSC25 & EF150791 & Cyanothece sp. ATCC 51142 & 92 & AF132771 \\
\hline & & HSC31 & EF150793 & Gloeocapsa sp. PCC 73106 & 94 & AF132784 \\
\hline & & HSC36 & EF150796 & LPP-group MBIC10087 & 97 & AB058225 \\
\hline & & HSC37 & EF150794 & Geitlerinema sp. PCC 7105 & 92 & AF132771 \\
\hline & & HSC22 & EF150797 & Xenococcus PCC 7305 & 92 & AF132783 \\
\hline & & HSC20 & EF150774 & Xenococcus sp. Cyano35 & 96 & DQ058859 \\
\hline & & HSC17 & EF150776 & Lyngbya hieronymusii & 94 & AF337650 \\
\hline & & HSC19 & EF150780 & Chroococcidiopsis sp. PCC 6712 & 94 & AJ344557 \\
\hline & & HSC3 & EF150785 & Dermocarpella incrassata & 98 & AJ344559 \\
\hline & & HSC34 & EF150783 & Gloeothece sp. KO11DG & 92 & AB067577 \\
\hline & & HSC24 & EF150784 & Uncultured Chroococcus sp. & 94 & DQ058856 \\
\hline
\end{tabular}

${ }^{a}$ Modified BG-11 media (Burns et al., 2004) used for the isolation of cyanobacteria.

${ }^{\mathrm{b}}$ Modified Luria-Bertani media (Burns et al., 2004) used for the isolation of heterotrophic bacteria.

Shannon-Wiener index for diversity (Table 2). Sequences were collected into operational taxonomic units by pair-wise identity (\% ID) with a furthestneighbour algorithm and a precision of 0.01 . The estimated coverage for all the libraries constructed was $\geqslant 50 \%$ (Table 2), and collector curves for coverage for all libraries approached asymptotic (data not shown). This indicated that the coverage of the populations was comprehensive for these samples, and the libraries were representative samples of the microbial diversity. The cutoff for differentiation of species was chosen as $97 \%$ sequence identity; however, this probably underestimated the total bacterial diversity. The Chao1 richness estimate for HPS2 was highest for the bacterial population. The number of observed species from the total bacterial library was 33 with a Chao1 estimate of 44.67 (36.45-73.40), indicating that when sampled to completion, there would be between 4 and 40 more species obtained. Only 10 taxa were obtained from the archaeal library and when sampled to completion 3-20 more species would be obtained. The cyanobacterial library was sampled to completion. The number of operational taxonomic units, Chao1 richness estimates and the Shannon-Wiener diversity estimates also indicated that total bacterial diversity from HPS2 was greater than the surrounding seawater, whereas the opposite was observed for the estimates of cyanobacterial diversity.

\section{Comparison with known Shark Bay stromatolite microbial communities}

Phylogenetic analysis of HPS2 and its surrounding seawater sequences was performed in ARB with the 

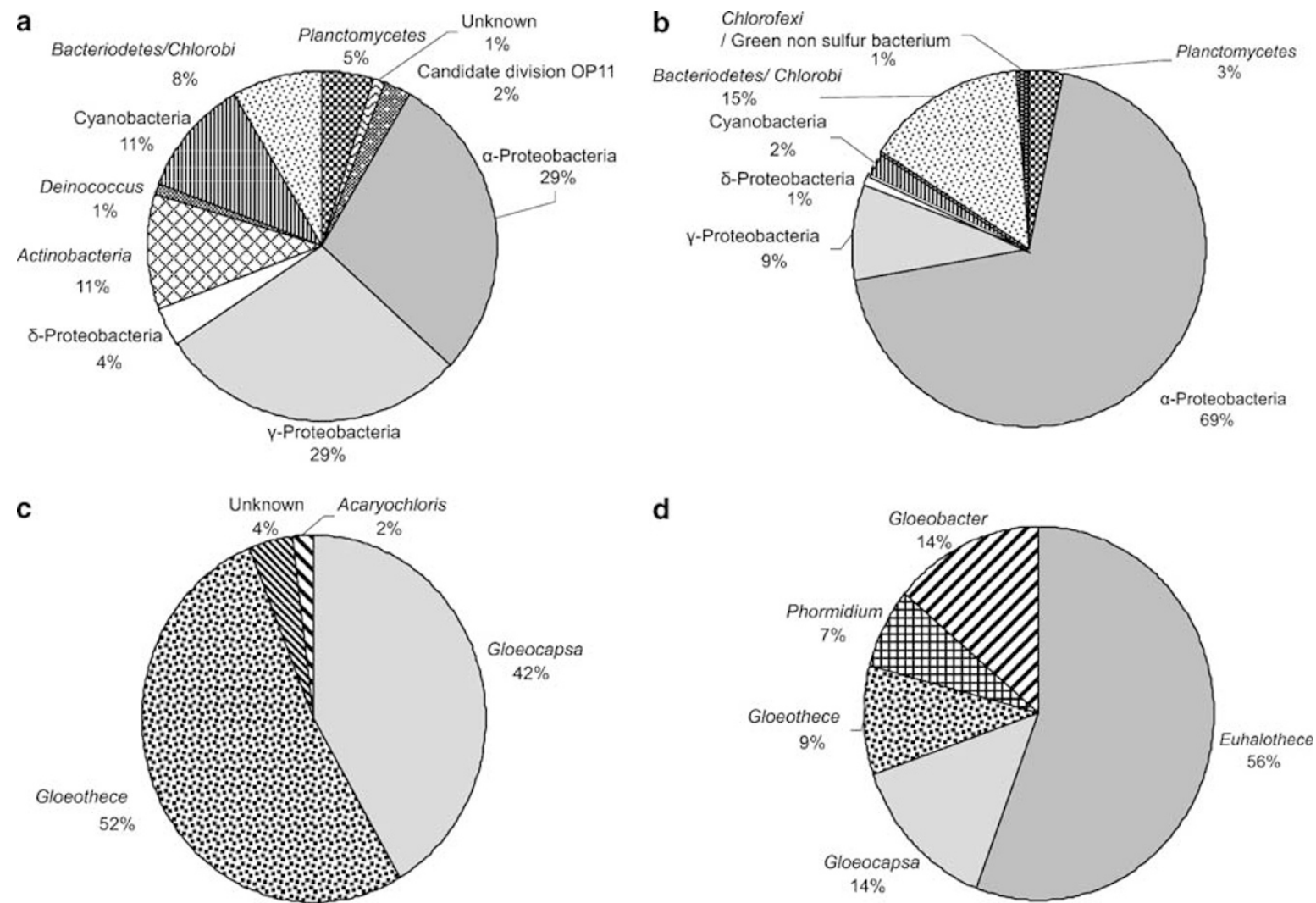

Figure 3 Comparison of the most abundant sequences in the 16S rDNA clone libraries constructed for total bacteria and cyanobacteria from the sample HPS2 and seawater. (a) Total bacteria in sample HSP2. (b) Total bacteria in surrounding seawater. (c) Cyanobacteria in sample HSP2. (d) Cyanobacteria in surrounding seawater.

Greengenes database of full-length non-chimaeric 16S rRNA gene sequences (DeSantis et al., 2006). Partial sequences from earlier studies on samples HPS1, HPDOM and HPIRR (Burns et al., 2004; Papineau et al., 2005) were included for comparison to obtain a comprehensive understanding of the microbial diversity in this environment. The phylogenetic trees in Figures 4-6 show the relative topologies of the sequences for the archaeal domain, the bacterial domain and for the cyanobacteria, respectively. As shown in Figure 4, all archael clones from HPS2, HPS1, HPDOM and HPIRR were related to Halobacteria from the Euryarchaeota. In particular, the Halococcus genus was represented by both clones and isolates from HPS2 and HPS1, an indication of their intrinsic persistence in this environment. In contrast to the archaeal population of HPS1, HPDOM and HPIRR, HPS2 contained no representatives of the Crenarchaeota. The results presented here indicate that there has been a decrease in the observed taxonomic units in archaeal diversity in these stromatolites possessing similar morphologies and from the same location. The halophilic archaeal sequences obtained from different samples over time generally had close phylogenetic affinities. However, no archaea were identified in the seawater surrounding the stromatolites using either culturing techniques or total DNA analyses.
Although it is possible that archaea are present in concentrations in the seawater that are below the limits of detection of the methods employed here, it would seem that these halophilic organisms are specific to these biosedimentary structures (Goh et al., 2006). The role of archaea in stromatolites is not well understood, and thus it is difficult to assess their contributions. Could archaea also contribute to stromatolite formation? Although we can only speculate at this stage, it has been shown that some Haloarchaeal species are also capable of fixing carbon dioxide (Javor, 1988). Furthermore, the association of sulphate-reducing bacteria with archaea can result in the coupling of methane oxidation with sulphate reduction and can also lead to carbonate precipitation (Michaelis et al., 2002).

Bacterial 16S rDNA sequence analysis revealed 16 groups belonging to $\alpha$-proteobacteria, $\gamma$-proteobacteria, $\delta$-proteobacteria, acidobacteria, Bacteriodetes/ chlorobi, two unknown clades, candidate division OP-11, firmicutes, candidate division TM6, planctomycetes, actinobacteria, chloroflexi, cyanobacteria, Deinococcus and thermotogales (Figure 5). Groups containing sequences from the seawater comprised the $\alpha$ - and $\gamma$-proteobacteria, Bacteriodetes/ chlorobi, planctomycetes, chloroflexi and cyanobacteria. The cyanobacterial cluster contained clones from both HPS2 and seawater (Figure 5). 
Table 2 Coverage, observed phylotype richness, richness and diversity indices for clone libraries constructed from HPS2 and seawater

\begin{tabular}{|c|c|c|c|c|c|c|c|c|c|c|c|}
\hline & \multirow{2}{*}{$\begin{array}{l}\text { Phylotype } \\
\text { cutoff (\%) }\end{array}$} & \multicolumn{5}{|c|}{ HPS2 } & \multicolumn{5}{|c|}{ Surrounding seawater } \\
\hline & & $\begin{array}{c}\text { No. of } \\
\text { clones } \\
\text { analysed }\end{array}$ & $\begin{array}{c}\text { Coverage } \\
\text { good } \\
(\%)^{\mathrm{a}}\end{array}$ & OTUs & $\begin{array}{c}\text { Richness } \\
\text { index } \\
\text { Chao1 } \\
(95 \% \text { CI })^{\mathrm{b}}\end{array}$ & $\begin{array}{c}\text { Diversity index } \\
\text { Shannon- } \\
\text { Wiener } \\
(95 \% \text { CI })^{\mathrm{c}}\end{array}$ & $\begin{array}{l}\text { No. of } \\
\text { clones } \\
\text { analysed }\end{array}$ & $\begin{array}{c}\text { Coverage } \\
\text { good } \\
(\%)^{\mathrm{a}}\end{array}$ & OTUs & $\begin{array}{c}\text { Richness } \\
\text { index } \\
\text { Chao1 } \\
(95 \% \text { CI })^{\mathrm{b}}\end{array}$ & $\begin{array}{c}\text { Diversity index } \\
\text { Shannon- } \\
\text { Wiener } \\
(95 \% \text { CI })^{\mathrm{c}}\end{array}$ \\
\hline \multirow[t]{6}{*}{ Archaea } & 100 & $\begin{array}{c}93 \\
\text { (659bp) }\end{array}$ & 84 & 15 & $18(15-37)$ & $2.01(1.78-2.25)$ & & & & & \\
\hline & 99 & & 86 & 13 & $18(13-45)$ & $1.57(1.29-1.85)$ & & & & & \\
\hline & 98 & & 89 & 10 & $13(10-32)$ & $1.12(0.85-1.40)$ & & & & NA & \\
\hline & 97 & & 89 & 10 & $13(10-32)$ & $1.12(0.85-1.40)$ & & & & & \\
\hline & 96 & & 89 & 10 & $13(10-32)$ & $1.12(0.85-1.40)$ & & & & & \\
\hline & 95 & & 90 & 9 & $12(9-31)$ & $0.93(0.66-1.19)$ & & & & & \\
\hline \multirow[t]{6}{*}{$\begin{array}{l}\text { Total } \\
\text { bacteria }\end{array}$} & 100 & $\begin{array}{c}87 \\
\text { (628 bp) }\end{array}$ & 59 & 35 & $47(39-74)$ & $3.21(3.00-3.41)$ & $\begin{array}{c}92 \\
\text { (667 bp) }\end{array}$ & 75 & 23 & $24(23-34)$ & $2.81(2.64-2.99)$ \\
\hline & 99 & & 60 & 34 & $46(38-73)$ & $3.19(2.99-3.38)$ & & 77 & 21 & $23(21-33)$ & $2.72(2.55-2.88)$ \\
\hline & 98 & & 60 & 34 & $46(38-73)$ & 3.19 (2.99-3.38) & & 77 & 21 & $23(21-33)$ & $2.72(2.55-2.88)$ \\
\hline & 97 & & 62 & 33 & $45(36-73)$ & $3.16(2.97-3.36)$ & & 78 & 20 & $22(20-32)$ & $2.62(2.44-2.80)$ \\
\hline & 96 & & 62 & 33 & $45(36-73)$ & $3.11(2.91-3.30)$ & & 78 & 20 & $22(20-32)$ & $2.62(2.44-2.80)$ \\
\hline & 95 & & 63 & 32 & $44(35-71)$ & $3.11(2.91-3.30)$ & & 79 & 19 & $21(19-31)$ & $2.53(2.35-2.71)$ \\
\hline \multirow[t]{6}{*}{$\begin{array}{l}\text { Cyano- } \\
\text { bacteria }\end{array}$} & 100 & $\begin{array}{c}96 \\
\text { (717 bp) }\end{array}$ & 92 & 7 & $7(7-13)$ & $1.33(1.17-1.49)$ & $\begin{array}{c}43 \\
\text { (781 bp) }\end{array}$ & 79 & 9 & $9(9-14)$ & $1.84(1.59-2.09)$ \\
\hline & 99 & & 92 & 7 & $7(7-13)$ & $1.33(1.17-1.49)$ & & 79 & 9 & $9(9-14)$ & $1.84(1.59-2.09)$ \\
\hline & 98 & & 92 & 7 & $7(7-13)$ & $1.33(1.17-1.49)$ & & 79 & 9 & $9(9-14)$ & $1.84(1.59-2.09)$ \\
\hline & 97 & & 93 & 6 & 6 & $1.23(1.14-1.42)$ & & 79 & 9 & $9(9-14)$ & $1.84(1.59-2.09)$ \\
\hline & 96 & & 93 & 6 & 6 & $1.23(1.14-1.42)$ & & 79 & 9 & $9(9-14)$ & $1.84(1.59-2.09)$ \\
\hline & 95 & & 93 & 6 & 6 & $1.23(1.14-1.42)$ & & 81 & 8 & $8(8-13)$ & $1.47(1.14-1.80)$ \\
\hline
\end{tabular}

Abbreviations: CI, confidence interval; OTUs, operational taxonomic units.

aThe coverage index was calculated by the method of Good (1953).

bThe richness index was calculated by the method of Chao1.

'The diversity index by the method of Shannon-Wiener was calculated using the software program DOTUR (Schloss and Handelsman, 2005).

These clones from HPS2 showed highest sequence identity to Cyanothece, Gloeocapsa and Phormidium, whereas clones from the surrounding seawater had highest sequence identity to Euhalothece. However, using cyanobacterial-specific PCR primers, a greater diversity of cyanobacteria was observed (Figure 6). Analyses of the total bacterial community in this study indicated that the identities of cultivated organisms also differed from those of the $16 \mathrm{~S}$ rDNA clone libraries. In particular, culturable Bacillus sp. appeared to dominate the Shark Bay stromatolites. One of the adaptive physiological responses to environmental stresses by Bacillus is spore formation (Nicholson, 2002), and the difficulty in extracting DNA from spores is a possible explanation for the lack of Bacillus 16S rRNA genes detected in the total genomic DNA from stromatolites in this and earlier studies. The majority of the stromatolite microbial communities were members of the proteobacteria/purple bacteria, firmicutes/Gram-positive bacteria, cyanobacteria and green sulphur bacteria, consistent with other reports on stromatolite-associated biodiversity (Bauld et al., 1979; Visscher et al., 1999; Reid et al., 2000). Bacteria belonging to the groups planctomycetes, proteobacteria/purple bacteria, cyanobacteria and the green sulphur bacteria were also identified in the surrounding seawater. These groups may therefore not be unique to these benthic geological communities; however, the dispersal of microorganisms from biofilms is a common phenomenon in the environment (Characklis, 1990; Brading et al., 1995).

The Shark Bay stromatolite cyanobacterial 16S rDNA sequences were affiliated to the orders Pleurocapsales, Chroococcales and Oscillatoriales. The Prochloron group was identified only from HPS1, whereas the surrounding seawater sequences were related to Chroococcales and Oscillatoriales. Three Pleurocapsales clades were identified to be Chroococcidiopsis (sequences from HPS1 and HPS2), Dermocarpella (sequences from HPS2) and Pleurocapsa (sequences from HPS2). Under the order Chroococcales, sequences from HPS1, HPS2 and the surrounding seawater were related to Gloeocapsa and Euhalothece spp. The Gloeothece group contained sequences from HPS2, HPIRR and HPDOM, whereas the Cyanothece group contained sequences from HPS1 and HPS2. Within the Oscillatoriales, most sequences from HPS1 belonged to Symploca, Plectonema and a novel clade of filamentous cyanobacteria. Sequences from HPS2 clustered with Leptolyngbya and Geitlerinema, whereas the HPIRR and HPDOM sequences clustered with Microcoleus sp. 


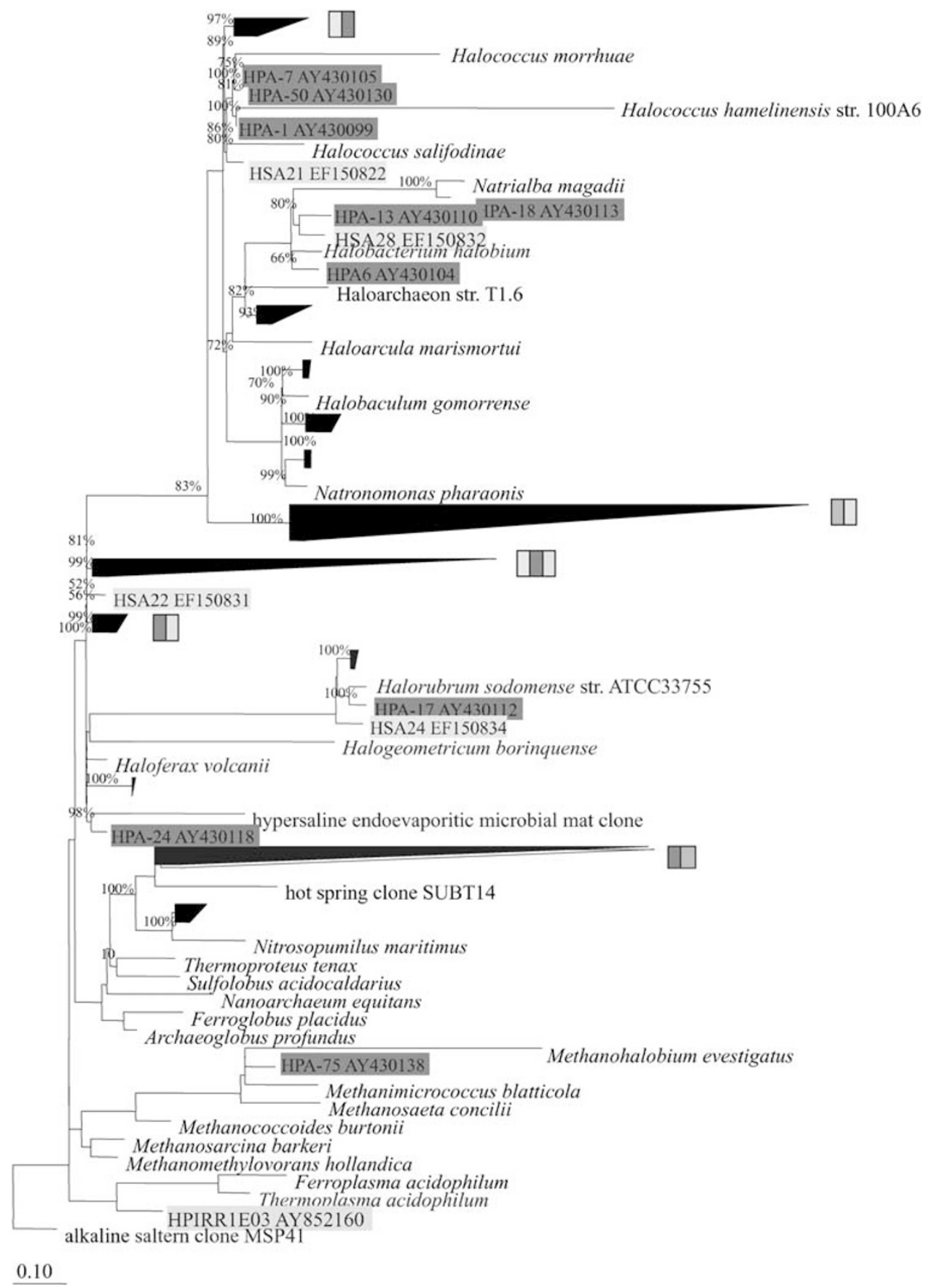

Figure 4 Phylogenetic relationships of archaea from Shark Bay intertidal stromatolites. Sequences from stromatolites HPS2, HPS1 (Burns et al., 2004), HPDOM and HPIRR (Papineau et al., 2005) were highlighted in yellow, red, orange and pink, respectively. A coloured box beside a filled triangle indicates that a group of sequences were clustered together. Only bootstrap values $>50 \%$ were considered significant. The scale bar represents 0.1 nucleotide changes per nucleotide position. SSU 16S rDNA sequences are available under GenBank accession numbers EF150811-EF150838. The color reproduction of this figure is available on the html full text version of the manuscript.

The identification of sequences related to Schizothrix sp. from HPS2 agrees with reports carried out on the microbial composition of the Bahaman stromatolites (Reid et al., 2000), and these and other filamentous cyanobacteria identified here may play roles in stromatolite formation in Shark Bay through the binding and trapping of sediments (Reid et al., 2000). This corroborates the recent detection of unicellular coccoid cyanobacteria in modern stromatolites (Macintyre et al., 2000). Although the specific coccoid cyanobacterium found to be involved in the boring and in-filling of Bahaman stromatolites (Solentia sp.) was not identified here, unicellular coccoid cyanobacterial isolates with $16 \mathrm{~S}$ rDNA sequences similar to Chroococcidiopsis sp., Xenococcus sp. and Dermocarpella sp. from the 


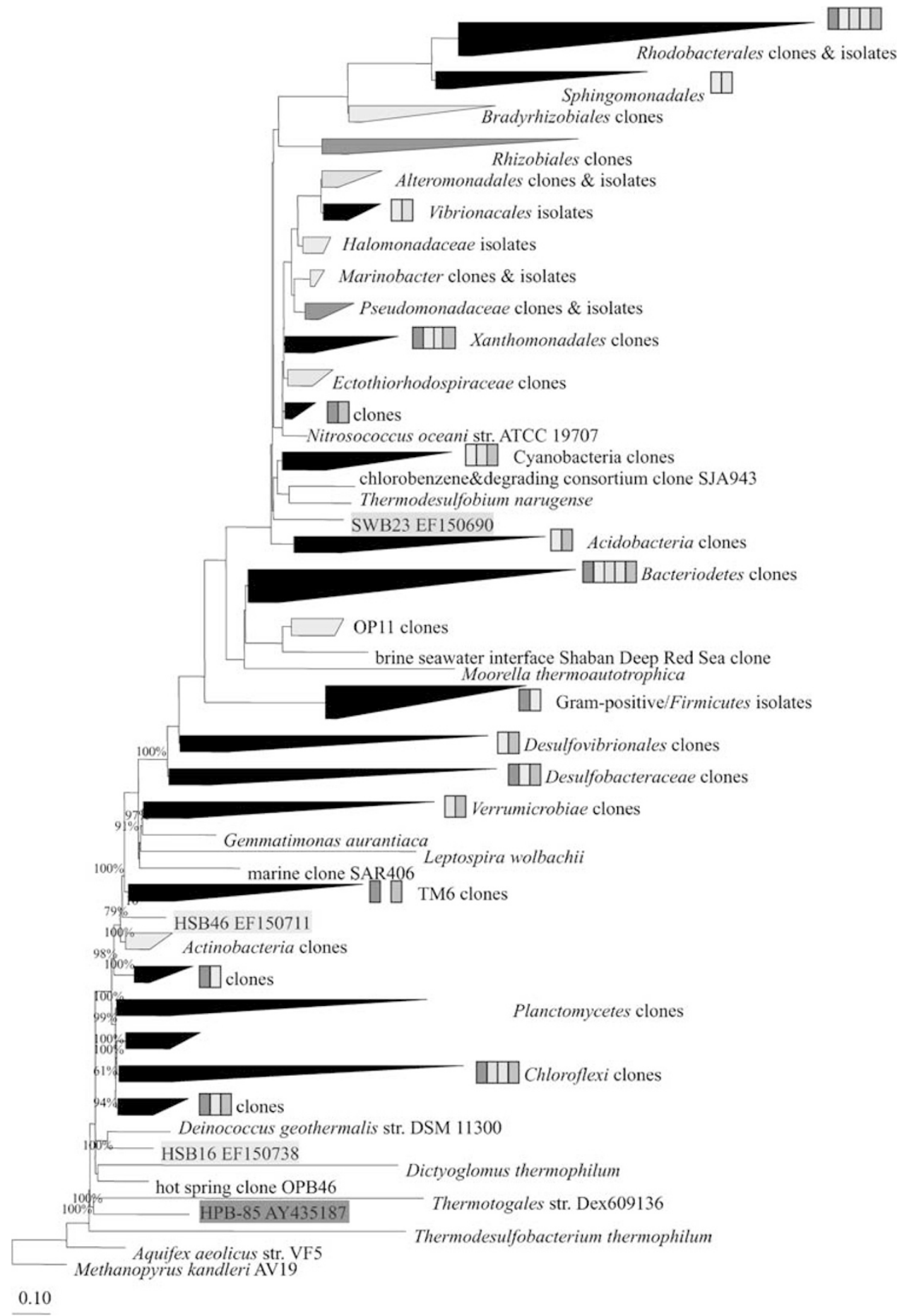

Figure 5 Phylogenetic relationships of total bacteria from Shark Bay intertidal stromatolites. Sequences from stromatolites HPS2, HPS1 (Burns et al., 2004), HPDOM and HPIRR (Papineau et al., 2005) and seawater were highlighted in yellow, red, orange, pink and blue, respectively. A coloured box beside a filled triangle indicates that sequences from more than one study were present. Only bootstrap values $>50 \%$ were considered significant. The scale bar represents 0.1 nucleotide changes per nucleotide position. SSU $16 \mathrm{~S}$ rDNA sequences are available under GenBank accession numbers EF150676-EF150762. The color reproduction of this figure is available on the html full text version of the manuscript.

same order (Pleurocapsales) were present in all the three Shark Bay samples. In particular, HPS2 indicated the presence of a higher diversity of unicellular cyanobacteria compared with HPS1, whereas the overall diversity in HPS2 was lower compared with the other studies. In addition to the involvement of filamentous cyanobacteria in the formation of stromatolites, the identification of these unicellular cyanobacteria sp. (Euhalothece sp., Gloeothece sp., Gloeocapsa sp. and Chroococci- 


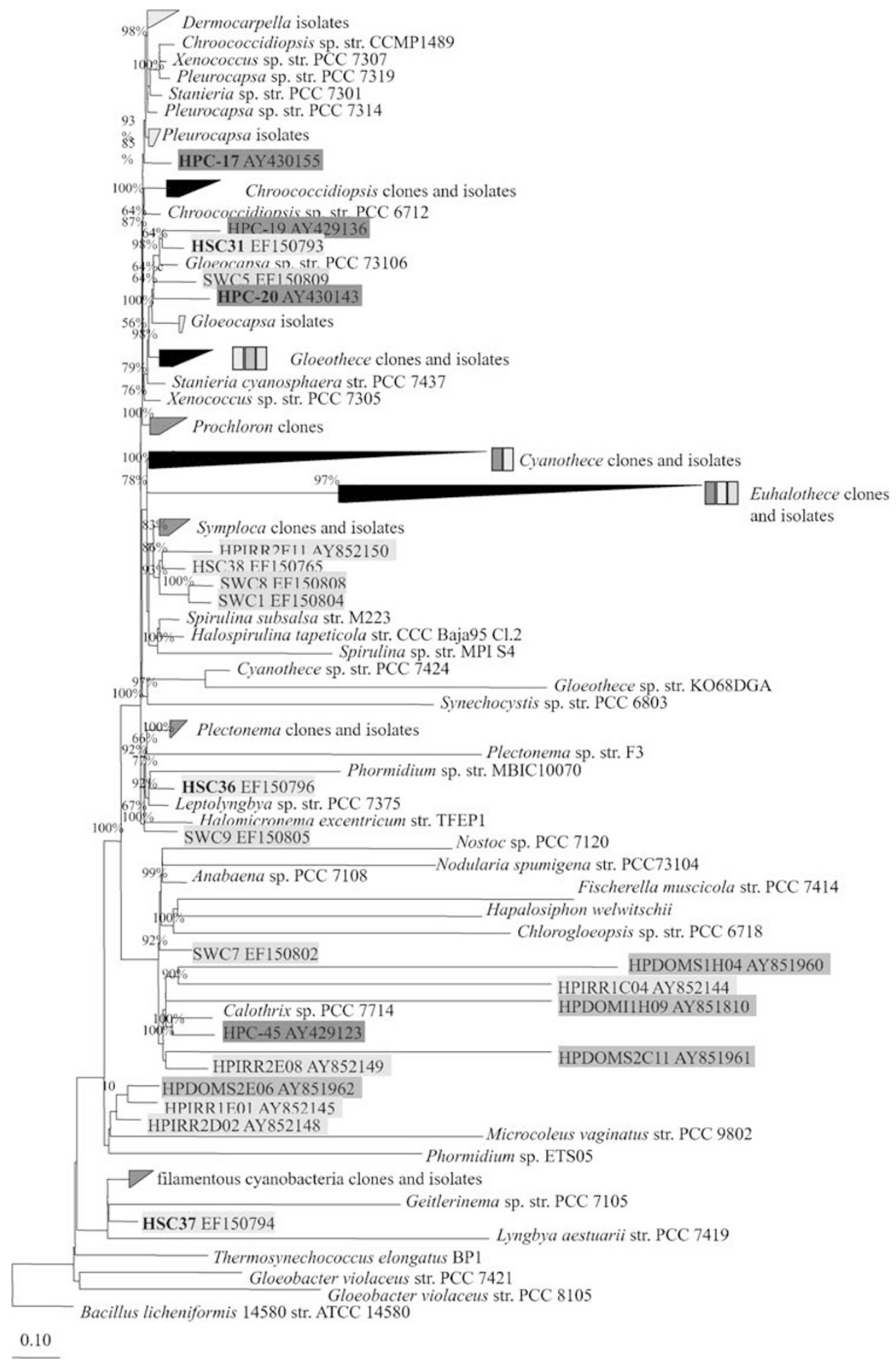

sp. str. PCC 7301

(

$64^{\circ}$ - Chroococcidionsis sn str. PCC 6712

S STPC-2

-7 Gloeocapsa isolates

पD Gloeothece clones and isolates 
shown to be involved in their formation (Visscher, 2000). In both the present and earlier studies on microbial diversity in the Shark Bay stromatolites, microbial groups were detected based on phylogenetic affinities. To determine the spatial distribution of these microorganisms, thin sections from the top $1 \mathrm{~cm}$ of stromatolite samples were analysed by confocal microscopy. In addition, archaeal probes were employed to investigate the distribution of halophilic archaea in Shark Bay stromatolites. Cyanobacteria were detected by the autofluorescence of phycocyanin whereas archaea and sulphate-reducing bacteria were detected using labelled specific DNA probes. Cyanobacteria were located throughout the stromatolite section and, in particular, at the surface (Figure 7a). Archaeal cells were not located on the surface of the stromatolites, but were closely associated with the cyanobacterial cells below the surface (Figure 7b). Sulphate-reducing bacteria were localized to the surface and intermediate layers of the stromatolite section, and were also in close association with cyanobacteria. Although the cyanobacteria formed a distinct layer on the surface, there were no other apparent discrete layers of microorganisms observed within the stromatolite sections (Figure 7). The archaea and sulphate-reducing bacteria were instead irregularly localized with the cyanobacterial cells (Figure 7c).

\section{Conclusion}

The microbial communities of modern stromatolites and surrounding seawater have been characterized and compared with the microorganisms identified earlier in this ecosystem. The presence of diverse metabolic groups of microorganisms indicated that this environment has a rich pool of genetic diversity and strongly suggests a high level of biological complexity in this ecosystem. The relative abundance of these microbial communities may influence the variety of geomorphologies observed; however, biases inherent in the present microbial and molecular analyses affords only limited quantitative interpretation of the data. The use of controlled and broadly accepted procedures ensures that the results can be readily related to similar investigations.

In terms of the microorganisms identified in both the stromatolites and the surrounding seawater, earlier studies have shown that the dispersal of biofilm members in surface water is common and is particularly relevant in this environment given that these microbial communities are subjected to abrasion, sloughing and erosion due to physical forces or nutrient depletion. Differences in microbial diversity of Shark Bay stromatolites apparent from the studies conducted to date may be in part due to these various environmental challenges leading to microbial succession, as shown to occur in the Bahaman stromatolites (Reid et al., 2000). The concept of succession is common in planktonic

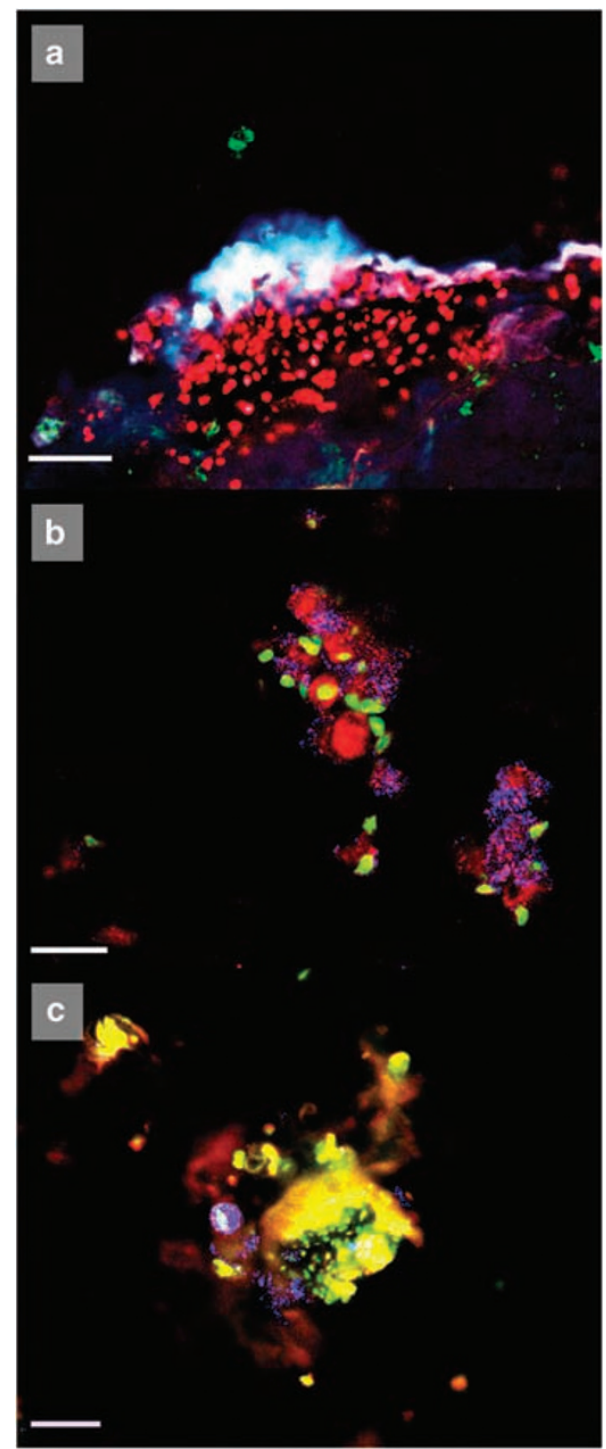

Figure 7 Krypton-Argon confocal images of FISH of crosssections of Shark Bay stromatolite samples. (a) Image of a stromatolite cross-sectioned vertical surface dominated by unicellular cyanobacteria that constitute the black surface layer (Figures 1a and c). The autofluorescence of cyanobacteria is denoted in red whereas DNA in the sample was stained by $\mathrm{SyBr}$ Green and is denoted in green. Scale $=10 \mu \mathrm{m}$. (b) FISH image of the interaction of cyanobacteria with archaea in the middle region of the stromatolite section with an FITC archaeal probe (green) and autofluorescence of cyanobacteria (red) is denoted in red. Scale $=5 \mu \mathrm{m}$. (c) FISH image of the middle region of the stromatolite section showing sulphate-reducing bacteria (stained with FITC-SRB probe green) with cyanobacteria (denoted in yellow due to the overlap between autofluorescence of cyanobacterial pigments, phycocyanin red and phycoerythrin green). Scale $=5 \mu \mathrm{m}$. Both (b) and c) were taken approximately $100 \mu \mathrm{m}$ below the surface. FISH, fluorescence in situ hybridization; FITC, fluorescein isothiocyanate.

cyanobacterial and other autotrophic communities (Stevenson, 1983), as it is in biofilm populations (Santegoeds et al., 1998; Jackson et al., 2001). If the measured fluxes in these stromatolite populations are real, certain metabolisms critical for the geological formation would also respond to the prevailing 
conditions. One such factor is hypersalinity of the environment. Salinity gradients are formed due to tidal flows and the evaporation of seawater in the intertidal regions of Hamelin Pool. These gradients result in the presence of microbial species adapted to different ranges of salinity and could result in a reduction in the diversity of bacterial and archaeal communities at higher salinities (Benlloch et al., 2002; Jungblut et al., 2005). High levels and fluctuations in salinity also result in an increase in biodiversity and favour the growth of halophilic microorganisms (Wieland and Kuhl, 2006; Abed et al., 2007). It is evident from this study, and regardless of time and the type of stromatolite, that certain phenotypic groups, such as both unicellular and filamentous cyanobacteria and halophilic archaea, are consistent components of these environments and therefore likely to be intrinsic to the development of the stromatolites at Shark Bay. The information presented here is a platform to examine other functional characteristics of these systems, including salt tolerance, cell signalling and secondary metabolism (Burns et al., 2005). This study has also confirmed the importance of microbial community analyses of the Hamelin Pool stromatolites to understand the relationship between microbial populations, the conservation and ecophysiology of this particular environment, and how this may correlate with the morphology of extant and extinct stromatolites.

\section{Acknowledgements}

The Australian Research Council and the National Science Foundation (US) are thanked for their financial support for this project.

\section{References}

Abed RMM, Kohls K, de Beer D. (2007). Effect of salinity changes on the bacterial diversity, photosynthesis and oxygen consumption of cyanobacterial mats from an intertidal flat of the Arabian Gulf. Environ Microbiol 9: 1384-1392.

Allwood AC, Walter MR, Balz S, Kamber BS, Marshall CP, Burch IW. (2006). Stromatolite reef from the Early Archaean era of Australia. Nature 441: 714-718.

Al-Qassab S, Lee WJ, Murray S, Simpson AGB, Patterson DJ. (2002). Flagellates from stromatolites and surrounding sediments in Shark Bay, Western Australia. Acta Protozool 41: 91-144.

Arp G, Reimer A, Reitner J. (2001). Photosynthesisinduced biofilm calcification and calcium concentrations in Phanerozoic oceans. Science 292: 1701-1704.

Awramik SM, Riding R. (1988). Role of algal eukaryotes in subtidal columnar stromatolite formation. Proc Natl Acad Sci USA 85: 1327-1329.

Bauld J, Chambers LA, Skyring GW. (1979). Primary productivity, sulfate reduction and sulfur isotope fractionation in algal mats and sediments of Hamelin Pool, Shark Bay, W.A. Aust J Mar Freshw Res 30: 753-764.
Benlloch S, López-López A, Casamayor EO, Øvreås L, Goddard V, Daae FL et al. (2002). Prokaryotic genetic diversity throughout the salinity gradient of a coastal solar saltern. Environ Microbiol 4: 349-360.

Brading M, Boyle J, Lappin-Scott H. (1995). Biofilm formation in laminar flow using Pseudomonas fluorescens EX 101. J Ind Microbiol 15: 297-304.

Burns BP, Goh F, Allen M, Neilan BA. (2004). Microbial diversity of extant stromatolites in the hypersaline marine environment of Shark Bay, Australia. Environ Microbiol 6: 1096-1101.

Burns BP, Seifert A, Goh F, Pomati F, Jungblut A-D, Serhat A et al. (2005). Genetic potential for secondary metabolite production in stromatolite communities. FEMS Microbiol Lett 243: 293-301.

Byerly GR, Lower DR, Walsh MM. (1986). Stromatolites from the 3,300-3,500-Myr Swaziland Supergroup, Barberton Mountain Land, South Africa. Nature 319: 489-491.

Chao A. (1984). Non-parametric estimation of the number of classes in a population. Scand J Stat 11: 265-270.

Characklis W. (1990). Process analysis. In: Characklis W, Marshall K (eds). Biofilms. John Wiley \& Sons, Inc.: New York. pp 50-51.

Cole JR, Chai B, Marsh TL, Farris RJ, Wang Q, Kulam SA et al. (2003). The Ribosomal Database Project (RDP-II): previewing a new autoaligner that allows regular updates and the new prokaryotic taxonomy. Nucleic Acids Res 31: 442-443.

DasSarma S, Fleischmann EM, Rodriguez-Valera F. (1995). Halophiles. In: Rob FT (ed). Archaea: A Laboratory Manual. CSHL Press: Cold Spring Harbour, USA, pp 225-230.

DeLong EF. (1992). Archaea in coastal marine environments. Proc Natl Acad Sci USA 89: 5685-5689.

DeSantis TZ, Hugenholtz P, Larsen N, Rojas M, Brodie EL, Keller K et al. (2006). Greengenes, a chimera-checked $16 \mathrm{~S}$ rRNA gene database and workbench compatible with ARB. Appl Environ Microbiol 72: 5069-5072.

Dravis JJ. (1983). Hardened subtidal stromatolites, Bahamas. Science 219: 385-386.

Garcia-Pichel F, Nubel U, Muyzer G. (1998). The phylogeny of unicellular, extremely halotolerant cyanobacteria. Arch Microbiol 169: 469-482.

Goh F, Leuko S, Allen MA, Bowman JP, Kamekura M, Neilan BA et al. (2006). Halococcus hamelinensis sp. nov., a novel halophilic archaeon isolated from stromatolites in Shark Bay, Australia. Int J Syst Evol Microbiol 56: 1323-1329.

Good IJ. (1953). The population frequencies of species and the estimation to the population parameters. Biometrika 40: 237-264.

Hoffman P. (1976). Stromatolite morphogenesis in Shark Bay, Western Australia. In: Walter MR (ed). Stromatolites. Elsevier Scientific Publishing Company: Amsterdam. pp 261-272.

Huber T, Faulkner G, Hugenholtz P. (2004). Bellerophon; a program to detect chimeric sequences in multiple sequence alignments. Bioinformatics 20: 2317-2319.

Jackson CR, Churchill PF, Roden EE. (2001). Successional changes in bacterial assemblage structure during epilithic biofilm development. Ecology 82: 555-566.

Javor BJ. (1988). $\mathrm{CO}_{2}$ fixation in halobacteria. Arch Microbiol 149: 433-440.

Jungblut AD, Hawes I, Mountfort D, Hitzfeld B, Dietrich DR, Burns BP et al. (2005). Diversity within cyanobacterial mat communities in variable salinity 
meltwater ponds of McMurdo Ice Shelf, Antarctica. Environ Microbiol 7: 519-529.

Leuko S, Allen MA, Goh F, Burns BP, Walter MR, Neilan BA. (2007). Analysis of intergenic spacer region length polymorphisms to investigate the halophilic archaeal diversity of stromatolites and microbial mat. Extremophiles 11: 203-210.

Logan BW, Cebulski DE. (1970). Carbonate sedimentation and environments, Shark Bay, Western Australia. Mem Amer Assoc Petrol Geol 13: 1-37.

Lowe DR. (1980). Stromatolites 3,400-Myr old from the Archean of Western Australia. Nature 284: 441-443.

Ludwig W, Strunk O, Westram R, Richter L, Meier H, Yadhukumar et al. (2004). ARB: a software environment for sequence data. Nucleic Acids Res 32: 1363-1371.

Macintyre IG, Prufert-Bebout L, Reid RP. (2000). The role of endolithic cyanobacteria in the formation of lithified laminae in Bahamian Stromalites. Sedimentology 47: 915-921.

Michaelis W, Seifert R, Nauhaus K, Treude T, Thiel V, Blumenberg $\mathrm{M}$ et al. (2002). Microbial reefs in the Black Sea fueled by anaerobic oxidation of methane. Science 297: 1013-1015.

Neilan BA, Burns BP, Relman D, Lowe DR. (2002). Molecular identification of cyanobacteria associated with stromatolites from distinct geographical locations. Astrobiology 2: 271-280.

Nicholson WL. (2002). Roles of Bacillus endospores in the environment. Cell Mol Life Sci 59: 410-416.

Nubel U, Garcia-Pichel F, Clavero E, Muyzer G. (2000). Matching molecular diversity and ecophysiology of benthic cyanobacteria and diatoms in communities along a salinity gradient. Environ Microbiol 2: 217-226.

Papineau D, Walker JJ, Mojzsis SJ, Pace NR. (2005). Composition and structure of microbial communities from stromatolites of Hamelin Pool in Shark Bay, Western Australia. Appl Environ Microbiol 71: 4822-4832.

Playford PE, Cockbain AE. (1976). Modern algal stromatolites at Hamelin Pool, a hypersaline barred basin in Shark Bay, Western Australia. In: Walter MR (ed). Stromatolites. Elsevier Scientific Publishing Company: Amsterdam, $101 \mathrm{p}$

Reid RP, Visscher PT, Decho AW, Stolz JF, Bebout BM, Dupraz C et al. (2000). The role of microbes in accretion, lamination and early lithification of modern marine stromatolites. Nature 406: 989-992.
Retief JD. (2000). Phylogenetic analysis using PHYLIP. Methods Mol Biol 132: 243-258.

Rippka R, Waterbury JB, Stanier RY. (1981). Isolation and purification of cyanobacteria: some general principles. In: Staff MP, Stolp HG, Truper HG, Barlows A, Schlegel HG (eds). The Prokaryotes. Springer-Verlag: Berlin. pp 212-220.

Sambrook J, Fritsch EF, Maniatis T. (1989). Molecular Cloning: a Laboratory Manual, 2nd edn, Cold Spring Harbor Laboratory Press: New York.

Santegoeds CM, Ferdelman TG, Muyzer G, Beer DD. (1998). Structural and functional dynamics of sulfate-reducing populations in bacterial biofilms. Appl Environ Microbiol 64: 3731-3739.

Schloss PD, Handelsman J. (2005). Introducing DOTUR, a computer program for defining operational taxonomic units and estimating species richness. Appl Environ Microbiol 71: 1501-1506.

Stevenson RJ. (1983). Effects of current and conditions simulating autogenically changing microhabitats on benthic diatom immigration. Ecology 64: 1515-1524.

Tillett D, Neilan B. (2000). Xanthogenate nucleic acid isolation from cultured and environmental cyanobacteria. J Phycol 36: 251-258.

Visscher PT. (2000). Microscale observations of sulfate reduction: correlation of microbial activity with lithified micritic laminae in modern marine stromatolites. Geology 28: 919-922.

Visscher PT, Gritzer RF, Leadbetter ER. (1999). Lowmolecular-weight sulfonates, a major substrate for sulfate reducers in marine microbial mats. Appl Environ Microbiol 65: 3272-3278.

Visscher PT, Reid RP, Bebout BM, Hoeft SE, Macintyre IG, Junior JAT. (1998). Formation of lithified micritic laminae in modern marine stromatolites (Bahamas): the role of sulfur cycling. Am Mineral 83: 1482-1493.

Wais AC. (1988). Recovery of halophilic archaebacteria from natural environments. FEMS Microbiol Ecol 53: 211-216.

Walter MR, Buick R, Dunlop JSR. (1980). Stromatolites 3,400-3,500 Myr old from the North Pole area, Western Australia. Nature 284: 443-445.

Wieland A, Kuhl M. (2006). Regulation of photosynthesis and oxygen consumption in a hypersaline cyanobacterial mat (Camargue, France) by irradiance, temperature and salinity. FEMS Microbiol Ecol 55: 195-210. 